\title{
Molecular monitoring of Plasmodium falciparum drug susceptibility at the time of the introduction of artemisinin-based combination therapy in Yaoundé, Cameroon: Implications for the future
}

Sandie Menard', Isabelle Morlais ${ }^{2,3}$, Rachida Tahar ${ }^{3,4}$, Collins Sayang ${ }^{3,5}$, Pembe Issamou Mayengue ${ }^{6}$, Xavier Iriart ${ }^{1}$, Françoise Benoit-Vical ${ }^{6}$, Brigitte Lemen ${ }^{7}$, Jean-François Magnaval ${ }^{8}$, Parfait Awono-Ambene ${ }^{3}$, Leonardo K Basco ${ }^{3,9}$ and Antoine Berry ${ }^{1 *}$

\begin{abstract}
Background: Regular monitoring of the levels of anti-malarial resistance of Plasmodium falciparum is an essential policy to adapt therapy and improve malaria control. This monitoring can be facilitated by using molecular tools, which are easier to implement than the classical determination of the resistance phenotype. In Cameroon, chloroquine (CQ), previously the first-line therapy for uncomplicated malaria was officially withdrawn in 2002 and replaced initially by amodiaquine (AQ) monotherapy. Then, artemisinin-based combination therapy (ACT), notably artesunate-amodiaquine (AS-AQ) or artemether-lumefantrine (AL), was gradually introduced in 2004. This situation raised the question of the evolution of $P$. falciparum resistance molecular markers in Yaoundé, a highly urbanized Cameroonian city.

Methods: The genotype of pfcrt 72 and 76 and pfmdr 186 alleles and pfmdr1 copy number were determined using real-time PCR in 447 P. falciparum samples collected between 2005 and 2009.

Results: This study showed a high prevalence of parasites with mutant pfcrt 76 (83\%) and pfmdr1 86 (93\%) codons. On the contrary, no mutations in the pfcrt 72 codon and no samples with duplication of the pfmdr 1 gene were observed.

Conclusion: The high prevalence of mutant pfcrt $76 \mathrm{~T}$ and pfmdr1 $86 \mathrm{Y}$ alleles might be due to the choice of alternative drugs ( $A Q$ and $A S-A Q$ ) known to select such genotypes. Mutant pfcrt 72 codon was not detected despite the prolonged use of $\mathrm{AQ}$ either as monotherapy or combined with artesunate. The absence of pfmdr1 multicopies suggests that AL would still remain efficient. The limited use of mefloquine or the predominance of mutant pfmdr1 86Y codon could explain the lack of pfmdr1 amplification. Indeed, this mutant codon is rarely associated with duplication of pfmdri gene. In Cameroon, the changes of therapeutic strategies and the simultaneous use of several formulations of ACT or other anti-malarials that are not officially recommended result in a complex selective pressure, rendering the prediction of the evolution of $P$. falciparum resistance difficult. This public health problem should lead to increased vigilance and regular monitoring.
\end{abstract}

Keywords: Malaria, Cameroon, pfcrt, pfmdr1, pfmdr1 copy number, Resistance, LNA probes

\footnotetext{
* Correspondence: berry.a@chu-toulouse.fr

'Service de Parasitologie-Mycologie, Centre Hospitalier Universitaire de

Toulouse et UMR152 UPS-IRD, Université de Toulouse, Toulouse, France

Full list of author information is available at the end of the article
} 


\section{Background}

Monitoring the level of Plasmodium falciparum resistance against anti-malarial drugs is one of the keys to a successful malaria control. Although controlled clinical trials are the best available tool for assessing the relevance of anti-malarial treatments, molecular monitoring offers some advantages. Studies on single-nucleotide polymorphisms (SNPs) and duplication of genes involved in resistance can be carried out with more ease and are less time-consuming. Furthermore, molecular monitoring may reveal trends, allowing anticipation in the changes of treatment policies.

In Cameroon, the first-line recommended therapy for uncomplicated malaria was chloroquine (CQ) until 2002 and amodiaquine (AQ) monotherapy between 2002 and 2004. In January 2004, the artesunate-amodiaquine (AS-AQ) combination was officially adopted and artemether-lumefantrine (AL) was added as an alternative artemisinin-based combination therapy (ACT) in 2006 [1]. In practice, AS-AQ and AL have been used nationwide since 2007. AS-AQ is widely available in public health care centres while AL is relatively less prescribed because of its low supply in the public sector at a subsidized price [2].

The amplification of $p f m d r 1$ gene is a common molecular marker of mefloquine (MQ) resistance. An increase in the $p f m d r 1$ copy number is associated with clinical failures to MQ [3] and in vitro resistance to lumefantrine, which is an amino-alcohol, like MQ [4]. The amplification of $p f m d r 1$ gene has also been demonstrated to decrease the susceptibility to artemisinin derivatives in the field as well as in laboratory-adapted P. falciparum strains [4-8]. Furthermore, a recent study in eastern Sudan reported an association between the carriage of parasites with increased $p f m d r 1$ copy number before treatment and recurrent parasitaemia after AL therapy [9].

In vitro, the pfmdr1 N86 wild-type allele, independently of the $p f m d r 1$ copy number, is associated with a higher susceptibility to lumefantrine and MQ $[3,10,11]$. In parallel, in the field, pfmdr1 N86 and pfcrt K76 wild-type alleles were selected by artemether-lumefantrine (AL) treatment whereas they were not selected by artesunate-amodiaquine (AS-AQ) or amodiaquine-sulphadoxine-pyrimethamine (AQ-SP) [12-15]. Conversely, the pfmdr1 86Y and pfcrt $76 \mathrm{~T}$ mutant alleles are associated with CQ resistance and also with AQ monotherapy failure [16-19]. Likewise, these haplotypes are selected by the association AS-AQ [20,21].

A pfcrt genotype conferring high levels of resistance to $\mathrm{AQ}$, corresponding to SVMNT haplotype of the codons 72-76, has been identified, first in Tanzania and more recently in Angola [22,23]. This haplotype, widely observed in Asia and South America, seems to be strongly selected by the use of AQ $[24,25]$.

The objective of this study was to determine the prevalence of $p f m d r 1$ multiple copies and mutant pfcrt 72 and 76 and pfmdr1 86 codons in Yaoundé, Cameroon at the time of the introduction of ACT. It is important to have a "molecular snapshot" of $P$. falciparum isolates at the beginning of this new anti-malarial therapeutic strategy, first, in order to make meaningful comparisons in the future and, secondly, to determine if there is any evidence of molecular mark suggesting a rapid evolution towards resistance.

\section{Methods}

\section{Study sites and origin of samples}

The study was carried out between 2005 and 2009, on a total of 447 samples from patients with a microscopy-confirmed diagnosis of uncomplicated falciparum malaria. The recruitment sites were in Yaoundé intra-muros ( $3^{\circ} 52^{\prime}$ $\left.\mathrm{N}, 11^{\circ} 31^{\prime} \mathrm{E}\right)$, including the healthcare centre of Nkolndongo ( 49 patients, median of three years old [0 month to 47 years]), the healthcare centre of Olembe (42 children, median of 2.5 years old [eight months to 12 years]), and the healthcare centre of Nlongkak (125 patients, median of two years old [six months to five years]). Two hundred and thirty-one samples were obtained from asymptomatic children aged from five to 11 years in Mfou $\left(3^{\circ} 43^{\prime} \mathrm{N}, 11^{\circ}\right.$ $\left.38^{\prime} \mathrm{E}\right), 26 \mathrm{~km}$ from the centre of Yaoundé. This study was reviewed and approved by the Cameroonian National Ethics Committee and Cameroonian Ministry of Public Health.

Before patients with a positive thick smear have received an ACT treatment, finger-pricked capillary blood sample was collected on different filter papers, Whatman (Whatman plc, Middlesex, UK) or IsoCode STIX (Schleicher \& Schuell, Keene, NH, USA). DNA from paper filters was extracted using the chelex-100 boiling method [26], concentrated by ethanol precipitation and frozen at $-20^{\circ} \mathrm{C}$ until amplification.

\section{Determination of pfmdr1 copy number}

To determine the copy number of $p f m d r 1$, a qPCR method described previously was used [27]. All samples were tested in triplicate in 96-well plates on a LightCycler $^{\circledR} 480$ system (Roche Diagnostics, Neuilly sur Seine, France). Each run included two control DNA samples of reference $P$. falciparum clones, FCM29/Cameroon and Dd2/Indochina, which are known to have one and twothree copies of $p f m d r 1$ gene, respectively [27].

\section{Genotyping of pfcrt and pfmdr1}

Genotyping of pfcrt 76 and pfmdr 186 codons was performed with a qPCR assay using Fluorescence Resonance Energy Transfer (FRET) hybridization probes and an analysis of the melting curve described previously $[28,29]$. Each run included two control DNA samples of $P$. falciparum: the CQ-susceptible F32/Tanzania strain with $p f c r t$ K76 and pfmdr1 N86 wild-type alleles and the 
CQ-resistant FCM29/Cameroon clone, carrying pfcrt $76 \mathrm{~T}$ and $p f m d r 186 \mathrm{Y}$ mutant alleles.

The detection of the pfcrt $72 \mathrm{~S}$ mutant allele was performed with a TaqMan probe-based genotyping assay the originality of which resides in the presence of Locked Nucleic Acid (LNA) inside the probes. LNA is a synthetic RNA analogue which, when integrated into an oligonucleotide, shows a strong affinity for their complementary targets [30]. Because of their thermal stability when hybridized to DNA, oligonucleotides containing LNA have a higher melting temperature $\left(\mathrm{T}_{\mathrm{m}}\right)$ and could be used as primers, probes or clamps to improve molecular detection [31-33]. In general, sequences from P. falciparum contain a high percentage of adenine (A) and thymine $(\mathrm{T})$ resulting in a low $\mathrm{Tm}$ and complicating molecular analysis. The introduction of LNA bases is a powerful tool to obtain discriminating probes with a moderate length and a probe hybridization that may occur during the annealing step in PCR. Consequently, this technique was particularly well suited for the experimental conditions described here. The $p f c r t$ gene was amplified by using primers P.falcA (5'-CAATT TTgTTTAAAgTTCTTTTAgCAA-3') and P.falcF (5'gTTCTTgTCTTggTAAATgTgCTCA-3'). To genotype the different alleles, the amplified product was detected with one of the specific TaqMan probes: AF233067 probe, 5'-YAK-AATTgTATTCATT + A + C + ACTT + $\mathrm{A}+\mathrm{CA}-\mathrm{BBQ}-3$ ' hybridized with the pfcrt $72 \mathrm{~S}$ mutant allele (SVMNT haplotype) and HM854027 probe, 5'LC670-AATTgTTTCAATT + A + C + ACATA + CABBQ-3' hybridized with the pfcrt $\mathrm{C} 72$ wild-type allele (CVIET haplotype) (the presence of a LNA nucleotide is preceded by the sign + ). The primers and probes were designed in collaboration with Tib MolBiol Syntheselabor (Berlin, Germany). Master mixes contained $1 \mu$ l GeneAmp $^{\circledR} 10 \times$ PCR Gold Buffer (Applied Biosystems, Branchburg, NJ), $2.5 \mathrm{mM} \mathrm{MgCl}_{2}, 200 \mu \mathrm{M}$ pooled dNTP, $500 \mathrm{nM}$ of forward and reverse primers, $250 \mathrm{nM}$ of each probe, $1 \mathrm{U}$ per reaction of AmpliTaq ${ }^{\circledR}$ Gold DNA Polymerase (Applied Biosystems) and $2 \mu$ lof template DNA for a total reaction volume of $10 \mu \mathrm{l}$. Each reaction plate was run with control DNA samples of $P$. falciparum, in particular the $7 \mathrm{G8} /$ Brazil strain known to harbour the pfcrt 72S mutated allele [34], F32/Tanzania and FCM29/ Cameroon as pfcrt C72 wild-type control [28], water and DNA of healthy patient, which served as negative external amplification controls. The multiplex TaqMan assay reactions were carried out in a LightCycler ${ }^{\circledR} 480$ Multiwell Plate 384 (Roche Diagnostics) with the following PCR programme: an initial step at $95^{\circ} \mathrm{C}$ for 12 minutes followed by 45 cycles of 10 seconds at $95^{\circ} \mathrm{C}$ and $45 \mathrm{sec}-$ onds at $60^{\circ} \mathrm{C}$. Data analysis for allelic discrimination was performed with the LightCycler ${ }^{\circledR} 480$ software (Roche Diagnostics).

\section{Statistical analysis}

The proportions were compared using $\chi^{2}$ test thanks to SigmaStat ${ }^{\circledR}$ software. The significance level $(P)$ was fixed at 0.05 .

\section{Results}

\section{Pfmdr1 copy number}

The copy number of $p f m d r 1$ was determined for only 215 isolates from healthcare centres of central Yaoundé because of the limited amount of DNA samples from Mfou. Regardless of where the tested isolates were collected, none of them were identified with $p f m d r 1$ gene amplification (Table 1). The estimated gene copy number from all analysed isolates was close to 1, with an average copy number of 1.05 and a standard deviation of 0.20 (data not shown).

\section{Pfmdr1 and pfcrt genotypes}

The prevalence of $p f m d r 1$ and $p f c r t$ alleles in blood samples obtained from different sites in Yaoundé is presented in Table 1. The frequencies of the pfmdr1 $86 \mathrm{Y}$ mutant genotype were $76 \%(153 / 201)$ and $84 \%(175 / 209)$ in Yaoundé and Mfou, respectively. Wild-type pfmdr1 N86 genotype was observed in 10\% (20/201) and 4\% (9/209) of isolates, and 14\% (28/201) and 12\% (25/209) of isolates presented a mixed genotype in Yaoundé and Mfou, respectively. No significant differences were observed between Yaoundé and Mfou.

The frequencies of $p f c r t 76 \mathrm{~T}$ mutant genotype were $71 \%(145 / 203)$ and 55\% (125/229), the pfcrt K76 wildtype allele was present in $19 \%(38 / 203)$ and $15 \%(35 / 229)$ and mixed pfcrt alleles occurred in 10\% (20/203) and 30\% $(69 / 229)$ of the isolates in Yaoundé and Mfou, respectively, with a significant difference $(\mathrm{p}<0.001)$.

Contrary to pfcrt 76, a significant difference $(\mathrm{p}=$ 0.042) of the distribution of the alleles was observed between Yaoundé and Mfou when all samples with mixed pfmdr1 86 genotype are classified in mutant group.

No significant differences were observed either between the different healthcare centres of Yaoundé or between the different times of sample collection (data not shown).

None of the 414 samples tested for the codon 72 of $p f c r t$ gene was found with the mutant $72 \mathrm{~S}$ allele (SVMNT haplotype).

\section{Discussion}

As elsewhere in the world, a very rapid development of resistance to anti-malarial drugs in Africa requires a regular monitoring in multiple and strategic points. With $53 \%$ of the population living in cities against 38\% WHO African region, Cameroon is a highly urbanized African country [35]. This demonstrates the importance of 
Table 1 Frequency of mutations and/or gene amplification in anti-malarial resistance markers pfmdr 1 and pfcrt in Plasmodium falciparum isolates in Yaoundé and Mfou, Cameroon

\begin{tabular}{|c|c|c|c|c|c|c|c|}
\hline \multirow[t]{2}{*}{ Genes and alleles } & \multicolumn{6}{|c|}{ Number of samples (\%) } & \multirow[t]{2}{*}{$\mathbf{P}$} \\
\hline & \multicolumn{2}{|c|}{ Both sites } & \multicolumn{2}{|c|}{ Yaoundé } & \multicolumn{2}{|c|}{$\begin{array}{l}\text { Mfou } \\
\text { (Suburb of Yaoundé) }\end{array}$} & \\
\hline \multicolumn{8}{|c|}{ pfmdr1 amplification $\left(\mathrm{n}^{\mathrm{a}}=215, \mathrm{n}^{\mathrm{b}}=\mathrm{NA}\right)$} \\
\hline 1 pfmdr1 copy number & 215 & $(100 \%)$ & 215 & $(100 \%)$ & NA & NA & NA \\
\hline$>1$ pfmdrl copy number & 0 & $(0 \%)$ & 0 & $(0 \%)$ & NA & NA & \\
\hline \multicolumn{8}{|l|}{ pfmdr1 codon $86\left(n^{a}=201, n^{b}=209\right)$} \\
\hline Mutant 86Y haplotype only & 328 & $(80 \%)$ & 153 & $(76 \%)$ & 175 & $(84 \%)$ & NS \\
\hline Mixed N86 and 86Y haplotypes & 53 & $(13 \%)$ & 28 & $(14 \%)$ & 25 & $(12 \%)$ & \\
\hline Wild-type N86 haplotype only & 29 & $(7 \%)$ & 20 & $(10 \%)$ & 9 & $(4 \%)$ & \\
\hline Total mutant $86 \mathrm{Y}$ haplotype ${ }^{c}$ & 381 & $(93 \%)$ & 181 & $(90 \%)$ & 200 & $(96 \%)$ & $0.042^{d}$ \\
\hline \multicolumn{8}{|l|}{ pfcrt codon $76\left(n^{a}=203, n^{b}=229\right)$} \\
\hline Mutant 76T haplotype only & 270 & $(62 \%)$ & 145 & $(71 \%)$ & 125 & $(55 \%)$ & $<0.001^{\mathrm{e}}$ \\
\hline Mixed K76 and 76T haplotypes & 89 & $(21 \%)$ & 20 & $(10 \%)$ & 69 & $(30 \%)$ & \\
\hline Wild-type K76 haplotype only & 73 & $(17 \%)$ & 38 & $(19 \%)$ & 35 & $(15 \%)$ & \\
\hline Total mutant 76T haplotype ${ }^{c}$ & 359 & $(83 \%)$ & 165 & $(81 \%)$ & 194 & $(85 \%)$ & $N S^{d}$ \\
\hline \multicolumn{8}{|l|}{ pfcrt codon $72\left(n^{a}=202, n^{b}=212\right)$} \\
\hline Mutant 72S haplotype & 0 & $(0 \%)$ & 0 & $(0 \%)$ & 0 & $(0 \%)$ & NS \\
\hline Wild-type C72 haplotype & 414 & $(100 \%)$ & 202 & $(100 \%)$ & 212 & $(100 \%)$ & \\
\hline
\end{tabular}

NA: not analysable because of the limited amount of DNA samples

NS: non significant

a: Number of total samples tested in the centre of Yaoundé

b: Number of total samples tested in the suburb of Yaoundé

c: Total mutant haplotype regroups single mutant haplotype and mixed haplotype, all samples with mixed genotype for the considered allele are classified in mutant group.

d: comparison of total mutant haplotypes versus wild-type haplotypes

e: comparison of mutant, wild-type and mixed haplotypes

epidemiological studies in large cities such as Yaoundé, which currently has a population of over $1,800,000$ inhabitants.

In the present study, a high prevalence of mutations associated with drug resistance was found in Yaoundé and its suburbs in both codon 76 of the pfcrt gene (83\%) and codon 86 of the $p f m d r 1$ gene (93\%) when all samples with mixed genotype were classified as mutant (Table 1). These results are in agreement with several other studies. Previous works of Basco et al carried out in Yaoundé showed that $70 \%$ of 157 P. falciparum clinical isolates had the mutant pfcrt 76T codon in 2001 [36], and a large majority of isolates ( $88 \%$ of 64 ) carried the $p f m d r 186 \mathrm{Y}$ mutant allele between 1997 and 2000 [37]. Similarly, Mbacham et al reported $77 \%$ and $76 \%$ prevalence of mutant pfcrt $76 \mathrm{~T}$ and $p f m d r 186 \mathrm{Y}$ codons, respectively, in samples collected during the period 2004-2006 in Yaoundé [38]. Despite different classification of double populations and techniques with different sensitivity, the prevalence of mutations appears to increase ( $p f c r t)$ or remains at a high and relatively stable level ( $p f m d r 1)$ until 2009 in spite of the official withdrawal of CQ from Cameroon in 2002. In some endemic areas, stopping the widespread use of CQ resulted in a return of chloroquine-sensitivity associated with the reappearance of wild-type genotypes. In the absence of drug pressure, P. falciparum wild-type haplotypes have a selective advantage over mutants. For example, in 1993, Malawi was the first sub-Saharan African country to replace CQ with SP nationwide in response to the high rates of CQresistant falciparum malaria. This change resulted in a decrease in the prevalence of the mutant pfcrt haplotype associated with CQ resistance from 85\% in 1992 to 13\% in 2000. For pfmdr1 86Y mutant codon, the same study showed similar results but with lower amplitude (from about $60 \%$ in 1993 to around $20 \%$ in 2000) [39]. The recovery of CQ-sensitivity phenotype and genotype was also observed elsewhere in Malawi [40], Kenya [41] and China [42].

This stability of mutant $p f c r t 76 \mathrm{~T}$ and $p f m d r 186 \mathrm{Y}$ genotypes observed in Yaoundé and suburb may be the result of many factors. First of all, the choice of the replacement treatment logically influences the type of selected isolates. The use of SP, which has no influence on the selection of mutant $p f c r t$ and $p f m d r 1$ genotypes, has been shown to favour, by a phenomenon of selective 
advantage, the reappearance of CQ-sensitive isolates harbouring wild-type $p f c r t$ K76 and $p f m d r 1$ N86 genotypes [39-41]. The use of AL or artesunate-mefloquine (AS-MQ) seems to favour the return to the predominance of wild-type pfmdr1 N86 genotype and, to a lesser extent, to the wild-type $p f c r t \mathrm{~K} 76$ genotype by an active selection [14,43-45]. Inversely, AQ, a close Mannich base analogue of $\mathrm{CQ}$, or AS-AQ promotes the maintenance of CQ-resistant isolates with the mutant $p f c r t$ and pfmdr1 genotypes by an active selective pressure [20,46], as observed in the present study. Whereas in East African countries like Malawi or Kenya, SP or AL had largely replaced CQ [47], in Yaoundé, in 2005, AQ was still prescribed as a first-line anti-malarial drug in $20 \%$ and $63 \%$ of adults and children under five years old, respectively [2], and AS-AQ in $4.5 \%$ and $1.5 \%$. AL was used only in $8.3 \%$ and $2.4 \%$, AS-MQ in $1.5 \%$ and $0.8 \%$, and SP in $5.8 \%$ and $0 \%$ of adults and children less than five years old, respectively [2].

Secondly, the changes of $P$. falciparum resistance phenotype and genotype after the withdrawal of CQ depend on the rapidity of drug replacement. For example, in Malawi where a profound and rapid return to CQ sensibility was observed, the change in drug policy from CQ to SP was swift and efficient, so that SP became the only available anti-malarial drug in less than one year after the implementation of the new drug policy. In contrast, these changes were progressive and lasted several years in many areas as in Cameroon. In fact, in Yaoundé, although the National Malaria Control Programme of Cameroon had replaced CQ by AQ in 2002 and then AQ monotherapy by AS-AQ since January 2004, CQ was still largely accessible through the informal outlets (e.g. food market) in August 2005 [2].

Finally, in a more general way, fitness loss of mutant P. falciparum might be associated with the development of compensatory mechanisms able to maintain mutant parasites even in the absence of drug pressure [48]. This feature might explain, at least in part, the persistence of mutant pfcrt codon in Southeast Asia and South America [49-51] and also in Cameroon, as described here.

In Mfou, a higher frequency of mixed $p f c r t$ haplotypes was observed at the expense of mutant $p f c r t$ population. This observation was not done for $p f m d r 1$ haplotypes. A possible reason for this observation is a drug pressure selection different from that existing in Yaoundé.

Since the probes used to detect the mutation in codon 76 of $p f c r t$ gene were not able to detect that of codon 72 , a new technique using LNA probes was developed in the present study to discriminate the mutant SVMNT haplotype (72S mutation) from the wild-type CVIET haplotype (C72 wild-type). Previous studies and data collected from countries like Bolivia or India suggested that AQ has an early and prominent role in the selection of parasites carrying SVMNT haplotype associated with drug resistance [24]. These parasites are highly resistant to AQ, but only moderately resistant to CQ. Contrary to CVIET haplotype, once the SVMNT haplotype emerges in a given parasite population and $C Q$ and $A Q$ are removed, the repopulation of sensitive strains may be very slow to occur [24]. As the SVMNT haplotype was recently described in Tanzania and Angola [22,23], it was important to verify whether this haplotype existed in Yaoundé. None of the samples tested for the codon 72 of pfcrt was found to carry the SVMNT haplotype. These results are contrary to what was observed in nearby African countries, such as in Ghana [52], Tanzania [22] and Angola [23] where the prevalence of this haplotype was between $3.9 \%$ and over $50 \%$. It is possible that the observed predominance of SVMNT haplotype in Angola is the result of frequent travels of Brazilian and Angolan citizens between the two countries [23], which is not the case in Cameroon. However, the monitoring of pfcrt codons 72-76 should be pursued because AQ has long been prescribed in Cameroon before and since the cessation of the use of CQ (2002) and until 2005 [2] and seems to have an important role in the selection of the SVMNT haplotype [22].

The amplification of $p f m d r 1$ gene has been more closely linked to MQ and halofantrine (HAL) resistance [53-55]. In this study, $p f m d r 1$ amplification was not observed in Yaoundé between 2005 and 2009. Elsewhere in Africa, the situation seems to be contrasted. In various studies conducted in East Africa, only four samples were found with pfmdr1 gene duplication, one in Kenya and three in Sudan (near the Ethiopian border) among 475 isolates tested (57 in Sudan [9], 72 in Kenya [46], 186 in Zanzibar [53] and 160 in Malawi [54]). In West Africa, on the one hand, none of 580 samples tested in Liberia and Guinea-Bissau between 1981 and 2005 was found to be duplicated [55]; on the other hand, two studies had identified in Burkina Faso, Ivory Coast, Togo and Madagascar, six pfmdr1 duplications among 112 samples tested [27,56]. In Central Africa, data are limited since only 32 samples were screened and all of them had a single copy of $p f m d r 1$ gene [27]. In this region, an exception is the study of Uhlemann et al who found the duplication of $p f m d r 1$ gene in five of 62 clinical isolates tested (8\%) in 1995 in Lambaréné, Gabon [57]. Four of these five patients harboured the wild-type N86 $p f m d r 1$ codon even though during this period $90 \%$ of isolates carried the mutant pfmdr1 codon 86 around Lambaréné [58]. However, in 2002 at the same study site, none of 37 samples tested had $p f m d r 1$ gene duplication. These observations on $p f m d r 1$ gene amplification in Lambaréné are difficult to explain outside of the possible selection of such a clone by previous clinical trials on the same site, using low dose of mefloquine [58-60]. Nevertheless, these data showed that $P$. falciparum isolates from Central Africa can have pfmdr1 gene duplication. 
The lack of $p f m d r 1$ gene duplication in Yaoundé may possibly be due to the very low use of MQ or HAL, which represented only $1.5 \%$ of first-line treatments against malaria in 2005 [2], but also partly to the high prevalence of the pfmdr1 Y86 mutant allele. Indeed, in Southeast Asia, pfmdr1 amplification has been suggested to be incompatible in the presence of the mutant pfmdr1 86Y allele [61]. However, the conclusion of that Asian study has not been confirmed in Africa, where the existence of parasites harbouring a duplicated pfmdr1 gene with mutant $86 \mathrm{Y}$ codon has been reported from Sudan [9], Gabon [57] and Ivory Coast [27,56].

The molecular analysis performed in the present study did not find any pfcrt $72 \mathrm{~S}$ mutation, which may be a good sign for the continued use of $\mathrm{AQ}$ in combination with AS. A regular evaluation of AS-AQ efficacy, in parallel with molecular surveillance, is required to ensure the utility of AS-AQ in Cameroon. This ACT contributes to the maintenance of a high prevalence of mutant pfcrt 76T and pfmdr1 86Y alleles. The pressing question is to predict how these parasites will evolve in the presence of AL pressure. Several scenarios can be envisioned. Firstly, they could behave like Southeast Asian isolates and will not progress to the duplication of $p f m d r 1$ gene in the absence of wild-type $p f m d r 1 \mathrm{~N} 86$ allele. Secondly, as already observed in some cases in Africa $[9,27,56,57]$, the parasites may acquire multicopies of $p f m d r 1$ despite the $p f m d r 186 \mathrm{Y}$ mutation. Only regular and exhaustive molecular monitoring of $P$. falciparum clinical isolates can provide the answer. However, the relevance of these results would be improved if they were associated with information on different antimalarial drugs that are really taken by the patients because these data often differ from the current national recommendation.

\begin{abstract}
Abbreviations
ACT: Artemisinin-based combination therapy; AL: Artemether-lumefantrine; AQ: Amodiaquine; AQ-SP: Amodiaquine-sulphadoxine-pyrimethamine; AS: Artesunate; AS-AQ: Artesunate-amodiaquine; AS-MQ: Artesunate-mefloquine; CQ: Chloroquine; FRET: Fluorescence resonance energy transfer; HAL: Halofantrine; LNA: Locked nucleic acid; MQ: Mefloquine; pfcrt: Plasmodium falciparum chloroquine resistance transporter; pfmdr1: Plasmodium falciparum multidrug resistance gene 1; qPCR: Quantitative polymerase chain reaction; SNP: Single-nucleotide polymorphism; SP: Sulphadoxine-pyrimethamine; Tm: Melting temperature.
\end{abstract}

\footnotetext{
Acknowledgements

The authors thank the patients and health staff of different health care centres in Yaoundé and Mfou for their participation in the study. The authors also thank Odile Mercereau-Puijalon for generously providing 7G8/ Brazil DNA. This work was supported by the Service de Coopération et d'Action Culturelle Français (SCAC) au Cameroun/Ministère des Affaires Etrangères Français (MAE), the European Union (Redox Antimalarial Drug Discovery, READ-UP, FP6-2004-LSH-2004-2.3.3-7, STREP no. 018602), and French Agence Nationale de la Recherche (project RES-ATQ, ANR-08-MIE024). CS was supported by a PhD grant of the Agence Universitaire de la Francophonie.
}

\section{Author details}

'Service de Parasitologie-Mycologie, Centre Hospitalier Universitaire de Toulouse et UMR152 UPS-IRD, Université de Toulouse, Toulouse, France. ${ }^{2}$ Institut de Recherche pour le Développement, UMR MIVEGEC, Montpellier, France. ${ }^{3}$ Laboratoire de Recherche sur le Paludisme, Organisation de Coordination pour la lutte contre les Endémies en Afrique Centrale (OCEAC), Yaoundé, Cameroon. ${ }^{4}$ Unité Mixte de Recherche 216, Institut de Recherche pour le Développement (IRD), Université Paris Descartes, Laboratoire de Parasitologie, Faculté de Pharmacie, Paris, France. ${ }^{5}$ Centre de Formation et de Recherche en Médecine et Santé Tropicale, Faculté de Médecine Nord, Université de la Méditerranée, Marseille, France. ${ }^{6}$ CNRS, LCC (Laboratoire de Chimie de Coordination), et Université de Toulouse Paul Sabatier, UPS, INPT, LCC, Toulouse, France. ${ }^{7}$ Centre d'Animation Sociale et Sanitaire (CASS), Yaoundé, Cameroon. ${ }^{8}$ CNRS UMR 5288 Anthropobiology, Université de Toulouse, Toulouse, France. ${ }^{9}$ Unité Mixte de Recherche 198, Institut de Recherche pour le Développement (IRD), Faculté de Médecine La Timone, Université de la Méditerranée, Marseille, France.

\section{Authors' contributions}

SM, PIM, carried out the molecular genetic studies. SM, AB, XI conceived and designed the study protocol and analysed the results. SM, AB, FBV, LKB drafted the manuscript. JFM, FBV, XI participated in its design and helped to draft the manuscript. RT, CS, LKB and BL participated in study design, supervised clinical and laboratory diagnosis in the health care centres, and collected blood samples in Nlongkak, Olembe, and Nkolndongo, IM and PAA had the same role for the blood samples collected in Mfou. All authors read and approved the final manuscript.

\section{Competing interests}

The authors declare that they have no competing interests.

Received: 24 January 2012 Accepted: 12 April 2012

Published: 12 April 2012

\section{References}

1. WHO: World Malaria Report 2008. 2008 [http://www.who.int/malaria/ publications/atoz/9789241563697/en/index.html].

2. Sayang C, Gausseres M, Vernazza-Licht N, Malvy D, Bley D, Millet P: Treatment of malaria from monotherapy to artemisinin-based combination therapy by health professionals in urban health facilities in Yaounde, central province, Cameroon. Malar J 2009, 8:176.

3. Price RN, Uhlemann AC, Brockman A, McGready R, Ashley E, Phaipun L, Patel R, Laing K, Looareesuwan S, White NJ, Nosten F, Krishna S: Mefloquine resistance in Plasmodium falciparum and increased pfmdr1 gene copy number. Lancet 2004, 364:438-447.

4. Sidhu AB, Uhlemann AC, Valderramos SG, Valderramos JC, Krishna S, Fidock DA: Decreasing pfmdr1 copy number in Plasmodium falciparum malaria heightens susceptibility to mefloquine, lumefantrine, halofantrine, quinine, and artemisinin. J Infect Dis 2006, 194:528-535.

5. Lim P, Alker AP, Khim N, Shah NK, Incardona S, Doung S, Yi P, Bouth DM, Bouchier C, Puijalon OM, Meshnick SR, Wongsrichanalai C, Fandeur T, Le Bras J, Ringwald P, Ariey F: Pfmdr1 copy number and arteminisin derivatives combination therapy failure in falciparum malaria in Cambodia. Malar J 2009, 8:11.

6. Carrara VI, Zwang J, Ashley EA, Price RN, Stepniewska K, Barends M, Brockman A, Anderson T, McGready R, Phaiphun L, Proux S, Van Vugt M, Hutagalung R, Maung Lwin K, Pyae Phyo A, Preechapornkul P, Imwong M, Pukrittayakamee S, Singhasivanon P, White NJ, Nosten F: Changes in the treatment responses to artesunate-mefloquine on the northwestern border of Thailand during 13 years of continuous deployment. PLoS One 2009, 4:e4551.

7. Begum K, Kim HS, Okuda Y, Wataya Y, Kimura M, Huruta T: Genomic analysis of mefloquine-resistant Plasmodium falciparum. Nucleic Acids Res Suppl 2002, 2:223-224.

8. Teuscher F, Gatton ML, Chen N, Peters J, Kyle DE, Cheng Q: Artemisinininduced dormancy in Plasmodium falciparum: duration, recovery rates, and implications in treatment failure. J Infect Dis 2010, 202:1362-1368.

9. Gadalla NB, Adam I, Elzaki SE, Bashir S, Mukhtar I, Oguike M, Gadalla A, Mansour F, Warhurst D, El-Sayed BB, Sutherland CJ: Increased pfmdr1 Copy Number and Sequence Polymorphisms in Plasmodium falciparum 
Isolates from Sudanese Malaria Patients Treated with ArtemetherLumefantrine. Antimicrob Agents Chemother 2011, 55:5408-5411.

10. Sidhu $A B$, Valderramos SG, Fidock DA: pfmdr1 mutations contribute to quinine resistance and enhance mefloquine and artemisinin sensitivity in Plasmodium falciparum. Mol Microbiol 2005, 57:913-926.

11. Duraisingh MT, Jones P, Sambou I, von Seidlein L, Pinder M, Warhurst DC: The tyrosine-86 allele of the pfmdr1 gene of Plasmodium falciparum is associated with increased sensitivity to the anti-malarials mefloquine and artemisinin. Mol Biochem Parasitol 2000, 108:13-23.

12. Martensson A, Stromberg J, Sisowath C, Msellem MI, Gil JP, Montgomery SM, Olliaro P, Ali AS, Bjorkman A: Efficacy of artesunate plus amodiaquine versus that of artemether-lumefantrine for the treatment of uncomplicated childhood Plasmodium falciparum malaria in Zanzibar, Tanzania. Clin Infect Dis 2005, 41:1079-1086.

13. Baliraine FN, Rosenthal PJ: Prolonged selection of pfmdr1 polymorphisms after treatment of falciparum malaria with artemether-lumefantrine in Uganda. J Infect Dis 2011, 204:1120-1124.

14. Sisowath C, Stromberg J, Martensson A, Msellem M, Obondo C, Bjorkman A, Gil JP: In vivo selection of Plasmodium falciparum pfmdr1 $86 \mathrm{~N}$ coding alleles by artemether-lumefantrine (Coartem). J Infect Dis 2005, 191:1014-1017

15. Some AF, Sere YY, Dokomajilar C, Zongo I, Rouamba N, Greenhouse B, Ouedraogo JB, Rosenthal PJ: Selection of known Plasmodium falciparum resistance-mediating polymorphisms by artemether-lumefantrine and amodiaquine-sulfadoxine-pyrimethamine but not dihydroartemisininpiperaquine in Burkina Faso. Antimicrob Agents Chemother 2010, 54:1949-1954.

16. Ochong EO, van den Broek IV, Keus K, Nzila A: Short report: association between chloroquine and amodiaquine resistance and allelic variation in the Plasmodium falciparum multiple drug resistance 1 gene and the chloroquine resistance transporter gene in isolates from the upper Nile in southern Sudan. Am J Trop Med Hyg 2003, 69:184-187.

17. Holmgren G, Gil JP, Ferreira PM, Veiga Ml, Obonyo CO, Bjorkman A: Amodiaquine resistant Plasmodium falciparum malaria in vivo is associated with selection of pfcrt 76T and pfmdr1 86Y. Infect Genet Evol 2006, 6:309-314

18. Happi $C T$, Gbotosho GO, Folarin OA, Bolaji OM, Sowunmi A, Kyle DE, Milhous W, Wirth DF, Oduola AM: Association between mutations in Plasmodium falciparum chloroquine resistance transporter and $P$. falciparum multidrug resistance 1 genes and in vivo amodiaquine resistance in P. falciparum malaria-infected children in Nigeria. Am J Trop Med Hyg 2006, 75:155-161.

19. Tinto H, Guekoun L, Zongo I, Guiguemde RT, D'Alessandro U, Ouedraogo JB: Chloroquine-resistance molecular markers (Pfcrt T76 and Pfmdr-1 Y86) and amodiaquine resistance in Burkina Faso. Trop Med Int Health 2008, 13:238-240.

20. Djimde AA, Fofana B, Sagara I, Sidibe B, Toure S, Dembele D, Dama S, Ouologuem D, Dicko A, Doumbo OK: Efficacy, safety, and selection of molecular markers of drug resistance by two ACTs in Mali. Am J Trop Med Hyg 2008, 78:455-461.

21. Nawaz F, Nsobya SL, Kiggundu M, Joloba M, Rosenthal PJ: Selection of parasites with diminished drug susceptibility by amodiaquine-containing antimalarial regimens in Uganda. J Infect Dis 2009, 200:1650-1657.

22. Alifrangis M, Dalgaard MB, Lusingu JP, Vestergaard LS, Staalsoe T, Jensen AT, Enevold A, Ronn AM, Khalil IF, Warhurst DC, Lemnge MM, Theander TG, Bygbjerg IC: Occurrence of the Southeast Asian/South American SVMNT haplotype of the chloroquine-resistance transporter gene in Plasmodium falciparum in Tanzania. J Infect Dis 2006, 193:1738-1741

23. Gama BE, Pereira-Carvalho GA, Lutucuta Kosi FJ, Almeida NKde Oliveira, Fortes F, Rosenthal PJ, Daniel-Ribeiro CT, de Fatima Ferreira-da-Cruz M: Plasmodium falciparum isolates from Angola show the StctVMNT haplotype in the pfcrt gene. Malar I 2010, 9:174.

24. Sa JM, Twu O: Protecting the malaria drug arsenal: halting the rise and spread of amodiaquine resistance by monitoring the pfcrt SVMNT type. Malar J 2010, 9:374.

25. Sa JM, Twu O, Hayton K, Reyes S, Fay MP, Ringwald P, Wellems TE: Geographic patterns of Plasmodium falciparum drug resistance distinguished by differential responses to amodiaquine and chloroquine. Proc Natl Acad Sci USA 2009, 106:18883-18889.
26. Plowe $\mathrm{CV}$, Wellems TE: Molecular approaches to the spreading problem of drug resistant malaria. Adv Exp Med Biol 1995, 390:197-209.

27. Witkowski B, Nicolau ML, Soh PN, Iriart X, Menard S, Alvarez M, Marchou B, Magnaval JF, Benoit-Vical F, Berry A: Plasmodium falciparum isolates with increased pfmdr1 copy number circulate in West Africa. Antimicrob Agents Chemother 2010, 54:3049-3051.

28. Vessiere A, Berry A, Fabre R, Benoit-Vical F, Magnaval JF: Detection by realtime PCR of the pfcrt T76 mutation, a molecular marker of chloroquineresistant Plasmodium falciparum strains. Parasitol Res 2004, 93:5-7.

29. Prugnolle F, Ollomo B, Durand P, Yalcindag E, Arnathau C, Elguero E, Berry A, Pourrut X, Gonzalez JP, Nkoghe D, Akiana J, Verrier D, Leroy E, Ayala FJ, Renaud F: African monkeys are infected by Plasmodium falciparum nonhuman primate-specific strains. Proc Natl Acad Sci USA 2011, 108:11948-11953.

30. Kumar R, Singh SK, Koshkin AA, Rajwanshi VK, Meldgaard M, Wengel J: The first analogues of LNA (locked nucleic acids): phosphorothioate-LNA and 2'-thio-LNA. Bioorg Med Chem Lett 1998, 8:2219-2222.

31. Fratczak A, Kierzek R, Kierzek E: LNA-modified primers drastically improve hybridization to target RNA and reverse transcription. Biochemistry 2009, 48:514-516.

32. Ugozzoli LA, Latorra D, Puckett R, Arar K, Hamby K: Real-time genotyping with oligonucleotide probes containing locked nucleic acids. Anal Biochem 2004, 324:143-152.

33. Senescau A, Berry A, Benoit-Vical F, Landt O, Fabre R, Lelievre J, Cassaing $S$, Magnaval JF: Use of a locked-nucleic-acid oligomer in the clampedprobe assay for detection of a minority pfcrt K76T mutant population of Plasmodium falciparum. J Clin Microbiol 2005, 43:3304-3308.

34. Valderramos SG, Valderramos JC, Musset L, Purcell LA, Mercereau-Puijalon O, Legrand E, Fidock DA: Identification of a mutant PfCRT-mediated chloroquine tolerance phenotype in Plasmodium falciparum. PLOS Pathog 2010, 6:e1000887.

35. WHO: Country Health System Fact Sheet 2006, Cameroon. 2006 [http:// www.afro.who.int/en/cameroon/country-health-profile.html].

36. Basco LK: Molecular epidemiology of malaria in Cameroon. XIII. Analysis of pfcrt mutations and in vitro chloroquine resistance. Am J Trop Med Hyg 2002, 67:388-391.

37. Basco LK, Ringwald P: Molecular epidemiology of malaria in Cameroon. X. Evaluation of pfmdr1 mutations as genetic markers for resistance to amino alcohols and artemisinin derivatives. Am J Trop Med Hyg 2002, 66:667-671.

38. Mbacham WF, Evehe MS, Netongo PM, Ateh IA, Mimche PN, Ajua A, Nji AM, Irenee D, Echouffo-Tcheugui JB, Tawe B, Hallett R, Roper C, Targett G, Greenwood B: Efficacy of amodiaquine, sulphadoxinepyrimethamine and their combination for the treatment of uncomplicated Plasmodium falciparum malaria in children in Cameroon at the time of policy change to artemisinin-based combination therapy. Malar J 2010, 9:34.

39. Kublin JG, Cortese JF, Njunju EM, Mukadam RA, Wirima JJ, Kazembe PN, Djimde AA, Kouriba B, Taylor TE, Plowe CV: Reemergence of chloroquinesensitive Plasmodium falciparum malaria after cessation of chloroquine use in Malawi. J Infect Dis 2003, 187:1870-1875.

40. Mita T, Kaneko A, Lum JK, Bwijo B, Takechi M, Zungu IL, Tsukahara T, Tanabe K, Kobayakawa T, Bjorkman A: Recovery of chloroquine sensitivity and low prevalence of the Plasmodium falciparum chloroquine resistance transporter gene mutation K76T following the discontinuance of chloroquine use in Malawi. Am J Trop Med Hyg 2003, 68:413-415.

41. Mwai L, Ochong E, Abdirahman A, Kiara SM, Ward S, Kokwaro G, Sasi P, Marsh K, Borrmann S, Mackinnon M, Nzila A: Chloroquine resistance before and after its withdrawal in Kenya. Malar J 2009, 8:106.

42. Wang X, Mu J, Li G, Chen P, Guo X, Fu L, Chen L, Su X, Wellems TE: Decreased prevalence of the Plasmodium falciparum chloroquine resistance transporter 76T marker associated with cessation of chloroquine use against P. falciparum malaria in Hainan, People's Republic of China. Am J Trop Med Hyg 2005, 72:410-414.

43. Sisowath C, Petersen I, Veiga MI, Martensson A, Premii Z, Bjorkman A Fidock DA, Gil JP: In vivo selection of Plasmodium falciparum parasites carrying the chloroquine-susceptible pfcrt K76 allele after treatment with artemether-lumefantrine in Africa. J Infect Dis 2009, 199:750-757.

44. Yang Z, Zhang Z, Sun X, Wan W, Cui L, Zhang X, Zhong D, Yan G, Cui L: Molecular analysis of chloroquine resistance in Plasmodium falciparum in Yunnan Province, China. Trop Med Int Health 2007, 12:1051-1060. 
45. Lekana-Douki JB, Dinzouna Boutamba SD, Zatra R, Zang Edou SE, Ekomy H, Bisvigou U, Toure-Ndouo FS: Increased prevalence of the Plasmodium falciparum pfmdr $186 \mathrm{~N}$ genotype among field isolates from Franceville, Gabon after replacement of chloroquine by artemether-lumefantrine and artesunate-mefloquine. Infect Genet Evol 2011, 11:512-517.

46. Holmgren G, Bjorkman A, Gil JP: Amodiaquine resistance is not related to rare findings of pfmdr1 gene amplifications in Kenya. Trop Med Int Health 2006, 11:1808-1812.

47. Laufer MK, Plowe CV: Withdrawing antimalarial drugs: impact on parasite resistance and implications for malaria treatment policies. Drug Resist Updat 2004, 7:279-288.

48. Walliker $\mathrm{D}$, Hunt $\mathrm{P}$, Babiker $\mathrm{H}$ : Fitness of drug-resistant malaria parasites. Acta Trop 2005, 94:251-259.

49. Cortese JF, Caraballo A, Contreras CE, Plowe CV: Origin and dissemination of Plasmodium falciparum drug-resistance mutations in South America. J Infect Dis 2002, 186:999-1006.

50. Vieira PP, Das Gracas Alecrim M, Da Silva LH, Gonzalez-Jimenez I, Zalis MG: Analysis of the pfcrt K76T mutation in Plasmodium falciparum isolates from the Amazon region of Brazil. J Infect Dis 2001, 183:1832-1833.

51. Zalis MG, Pang L, Silveira MS, Milhous WK, Wirth DF: Characterization of Plasmodium falciparum isolated from the Amazon region of Brazil: evidence for quinine resistance. Am J Trop Med Hyg 1998, 58:630-637.

52. Mehlotra RK, Mattera G, Bockarie MJ, Maguire JD, Baird JK, Sharma YD, Alifrangis M, Dorsey G, Rosenthal PJ, Fryauff DJ, Kazura JW, Stoneking M, Zimmerman PA: Discordant patterns of genetic variation at two chloroquine resistance loci in worldwide populations of the malaria parasite Plasmodium falciparum. Antimicrob Agents Chemother 2008, 52:2212-2222.

53. Sisowath $C$, Ferreira PE, Bustamante $L Y$, Dahlstrom $S$, Martensson $A$, Bjorkman A, Krishna S, Gil JP: The role of pfmdr1 in Plasmodium falciparum tolerance to artemether-lumefantrine in Africa. Trop Med Int Health 2007, 12:736-742.

54. Nkhoma S, Nair S, Mukaka M, Molyneux ME, Ward SA, Anderson TJ: Parasites bearing a single copy of the multi-drug resistance gene (pfmdr-1) with wild-type SNPs predominate amongst Plasmodium falciparum isolates from Malawi. Acta Trop 2009, 111:78-81.

55. Ursing J, Kofoed PE, Rombo L, Gil JP: No pfmdr1 amplifications in samples from Guinea-Bissau and Liberia collected between 1981 and 2004. J Infect Dis 2006, 194:716-718, author reply 718-719.

56. Basco LK, Le Bras J, Rhoades Z, Wilson CM: Analysis of pfmdr1 and drug susceptibility in fresh isolates of Plasmodium falciparum from subsaharan Africa. Mol Biochem Parasitol 1995, 74:157-166.

57. Uhlemann AC, Ramharter M, Lell B, Kremsner PG, Krishna S: Amplification of Plasmodium falciparum multidrug resistance gene 1 in isolates from Gabon. J Infect Dis 2005, 192:1830-1835.

58. Mawili-Mboumba DP, Kun JF, Lell B, Kremsner PG, Ntoumi F: Pfmdr1 alleles and response to ultralow-dose mefloquine treatment in Gabonese patients. Antimicrob Agents Chemother 2002, 46:166-170.

59. Radloff PD, Philipps J, Nkeyi M, Sturchler D, Mittelholzer ML, Kremsner PG: Arteflene compared with mefloquine for treating Plasmodium falciparum malaria in children. Am J Trop Med Hyg 1996, 55:259-262.

60. Lell B, Lehman LG, Schmidt-Ott JR, Sturchler D, Handschin J, Kremsner PG: Malaria chemotherapy trial at a minimal effective dose of mefloquine/ sulfadoxine/pyrimethamine compared with equivalent doses of sulfadoxine/pyrimethamine or mefloquine alone. Am J Trop Med Hyg 1998, 58:619-624.

61. Woodrow CJ, Krishna S: Antimalarial drugs: recent advances in molecular determinants of resistance and their clinical significance. Cell Mol Life Sci 2006, 63:1586-1596.

doi:10.1186/1475-2875-11-113

Cite this article as: Menard et al:: Molecular monitoring of Plasmodium

falciparum drug susceptibility at the time of the introduction of artemisinin-based combination therapy in Yaoundé, Cameroon: Implications for the future. Malaria Journal 2012 11:113.

\section{Submit your next manuscript to BioMed Central and take full advantage of:}

- Convenient online submission

- Thorough peer review

- No space constraints or color figure charges

- Immediate publication on acceptance

- Inclusion in PubMed, CAS, Scopus and Google Scholar

- Research which is freely available for redistribution 